\title{
Diagnosis by Volatile Organic Compounds in Exhaled Breath from Lung Cancer Patients Using Support Vector Machine Algorithm
}

\author{
Yuichi Sakumura ${ }^{1, *}$, Yutaro Koyama ${ }^{1}$, Hiroaki Tokutake ${ }^{1}$, Toyoaki Hida ${ }^{2}$, Kazuo Sato ${ }^{3}$, \\ Toshio Itoh ${ }^{4}$, Takafumi Akamatsu ${ }^{4}$ and Woosuck Shin ${ }^{4, *}$ \\ 1 Department of Information Science and Technology, Aichi Prefectural University, Nagakute 480-1198, Japan; \\ sonic.h.0715@gmail.com (Y.K.); tokusanpc@gmail.com (H.T.) \\ 2 Department of Thoracic Oncology, Aichi Cancer Center, 1-1 Kanokoden, Chikusa-ku, \\ Nagoya 464-8681, Japan; 107974@aichi-cc.jp \\ 3 Department of Mechanical Engineering, Aichi Institute of Technology, Toyota 470-0392, Japan; \\ sato@aitech.ac.jp \\ 4 Department of Materials and Chemistry, National Institute of Advanced Industrial Science and \\ Technology (AIST), Shimo-Shidami, Moriyama-ku, Nagoya 463-8560, Japan; itoh-toshio@aist.go.jp (T.I.); \\ t-akamatsu@aist.go.jp (T.A.) \\ * Correspondence: sakumura@ist.aichi-pu.ac.jp (Y.S.); w.shin@aist.go.jp (W.S.); \\ Tel.: +81-561-64-1111 (Y.S.); +81-52-736-7107 (W.S.)
}

Academic Editor: W. Rudolf Seitz

Received: 15 November 2016; Accepted: 29 January 2017; Published: 4 February 2017

\begin{abstract}
Monitoring exhaled breath is a very attractive, noninvasive screening technique for early diagnosis of diseases, especially lung cancer. However, the technique provides insufficient accuracy because the exhaled air has many crucial volatile organic compounds (VOCs) at very low concentrations (ppb level). We analyzed the breath exhaled by lung cancer patients and healthy subjects (controls) using gas chromatography/mass spectrometry (GC/MS), and performed a subsequent statistical analysis to diagnose lung cancer based on the combination of multiple lung cancer-related VOCs. We detected 68 VOCs as marker species using GC/MS analysis. We reduced the number of VOCs and used support vector machine (SVM) algorithm to classify the samples. We observed that a combination of five VOCs $\left(\mathrm{CHN}\right.$, methanol, $\mathrm{CH}_{3} \mathrm{CN}$, isoprene, 1-propanol) is sufficient for $89.0 \%$ screening accuracy, and hence, it can be used for the design and development of a desktop GC-sensor analysis system for lung cancer.
\end{abstract}

Keywords: lung cancer; volatile organic compounds (VOCs); exhaled air; screening; gas chromatographymass spectrometry analysis; support vector machine (SVM)

\section{Introduction}

Balancing the quality of life and sharp increase in healthcare expenses is an important social issue. Breath analysis is a noninvasive technique, allows easy sample collection, and provides quick results; thus, it is gaining attention as a new diagnostic technology. Breath is composed mainly of nitrogen (the most abundant gas in the atmosphere) along with carbon dioxide produced by respiration, oxygen that was not consumed, and water vapor. In addition, it contains more than 100 additional types of gas components in different concentrations, which provide information that may be useful to monitor health conditions such as disease or stress. Gas-sensing technologies (e.g., selective and quantitative gas detection) are necessary to measure the concentration of different gas species related to halitosis, metabolism, and diseases. 
Some volatile organic compounds (VOCs) in exhaled breath are expected to be useful as biomarkers for diseases, including cancer [1,2]. Lung cancer has become a major concern in Japan because it is the top cause of death by disease in the country. Lung cancer has a high mortality rate because it has often progressed by the time a patient perceives any symptoms and is diagnosed. If lung cancer is detected earlier, it can be treated by surgery and subsequent chemotherapy. However, no good early diagnostics are available. It is difficult to detect lung cancer using chest X-ray radiography (CXR) [3]; thus, diagnosis is provided after sputum analysis and extensive examination with low-dose computed tomographic (LDCT) scanning.

Monitoring the breath is one of the most noninvasive screening techniques available for early diagnosis [4-11]; however, this method is limited by its poor accuracy because the exhaled breath has many VOCs at very low concentrations (ppb level), and there is no clear protocol of breath sampling [12]. Gas chromatography-mass spectrometry (GC/MS) is one of the best methods for detecting low-concentration VOCs; however, this method is expensive, and the instrumentation is not portable.

If some specific VOCs have sufficient information for diagnosing diseases, one could measure these VOCs with relatively high resolution using a suitable technique, and detection of the other gas species would not be necessary. VOCs have been reported as biomarkers for lung cancer [5,8,13-18]; however, various other compounds have also been reported as possible biomarkers, suggesting disagreement in literature. For these reasons, VOC patterns (i.e., not single VOCs, but combinations of several VOCs) should be used for exhaled breath analysis for the diagnosis of diseases [5,8,13-19]. Here, we seek to determine which gas species are more important and how many are necessary to ensure system reliability. The optimized prototype system should be of reasonable size and cost; the number of gas species used should be fewer than 10, and the system should be able to detect the essential components of those gases.

Recent studies have demonstrated computer-assisted diagnosis by measuring multiple VOCs. Various algorithms have been applied to examine lung cancer diagnosis using multiple VOCs; for example, forward stepwise discriminant analysis [5,13], partial least-squares regression [14], logistic regression [15,18], random forest classification [20], weighted digital sum discriminator [21], and linear canonical discriminant analysis with principal component analysis (PCA) [17]. The support vector machine (SVM) is a powerful supervised machine learning model based on statistical learning theory [22]. SVM has been successfully used in the field of brain science to classify brain tumors [23,24], Alzheimer's disease [25,26], and depression $[27,28]$, based on magnetic resonance imaging (MRI) data. SVM-based research has been performed for VOC analysis to classify lung cancer cells [29], smoking subjects [30], patients with chronic obstructive pulmonary disease [31], and patients with head-and-neck cancer [32]. Many studies have examined VOCs in the exhaled breath; however, SVM-based analysis with a raw VOC data set has not been examined to select the essential VOCs for diagnosing lung cancer.

We have developed a prototype system for monitoring exhaled breath that can replace GC/MS. It combines a highly sensitive gas sensor with GC to separate the gases. The prototype system has simple GC columns, a simple gas-condenser unit, and $\mathrm{SnO}_{2}$-based semiconductor gas sensors [33]. For further development of the prototype system, we analyzed the VOCs detected in the breath of lung cancer patients and healthy subjects (controls) to determine the most effective combination of VOCs for diagnosing lung cancer. We applied a nonlinear SVM classification to various subsets of the VOCs detected by the GC/MS system and did not preprocess the VOCs by PCA because it is difficult to select VOCs from the principal components, which are composed of the multiple VOC features, and validate diagnose ability by the selected VOCs. We also did not select VOCs that have a significant difference in concentration between cancer and healthy samples. It is likely that the diagnosis is possible by the VOCs that have no significant difference in VOC concentration. We performed leave-one-out cross-validation of the samples (patients and controls) for each of the combinations of VOCs and evaluated the true positive rate (sensitivity) and accuracy of diagnosis for the left-out sample. We found that a specific combination of a small number of VOCs could diagnose lung cancer with a high accuracy. 


\section{Breath Gas Analysis and Diagnosis Methods}

\subsection{Breath Collection and Analysis}

After obtaining approval from the local ethics committees of Aichi Cancer Center and the National Institute of Advanced Industrial Science and Technology and written informed consent from the participants, 107 patients with lung cancer and 29 healthy individuals were enrolled in this study. The stage and histology of the lung cancer were omitted and it was simply labeled as "lung cancer". The numbers of patients with stage I, II, III and IV lung cancer were 55, 15, 28 and 9, respectively. The numbers of smoker, ex-smoker, and nonsmoker for lung cancer patients were 47,15 and 45 and those for healthy individuals were 5, 3 and 21, respectively.

Human breath and ambient air in a room at Aichi Cancer Center were collected using an Analytic Barrier Bag (Omi Odor-Air Service Corp., Omihachiman, Japan). Before sample collection, the volunteers did not eat or smoke for several hours and they stayed in the room for at least $10 \mathrm{~min}$. All volunteers blew their alveolar breath into a $1 \mathrm{~L}$ Analytic Barrier Bag immediately after they exhaled their respiratory tract air in a consultation room. The breath was analyzed using a GCMS-QP2010 instrument (Shimadzu, Kyoto, Japan) equipped with a TD-2 gas-condensing unit (Shimadzu) (Figure 1). The TD-2 has a gas aspiration unit and a cold trap for condensation of low-concentration VOCs. The GC/MS system used helium gas (99.9995\% purity, Taiyo Nippon Sanso, Japan) as the carrier gas. A DB-1 series 123-1063 gas column (Agilent Technologies, Santa Clara, CA, USA) was used. The background VOCs in the room air and the VOCs from the exhaled air were analyzed, and the concentrations of background VOCs were subtracted from the results for the exhaled air prior to data analysis. The concentrations of these VOCs were excluded from the results of breath analysis in this study. The details are reported elsewhere [33].

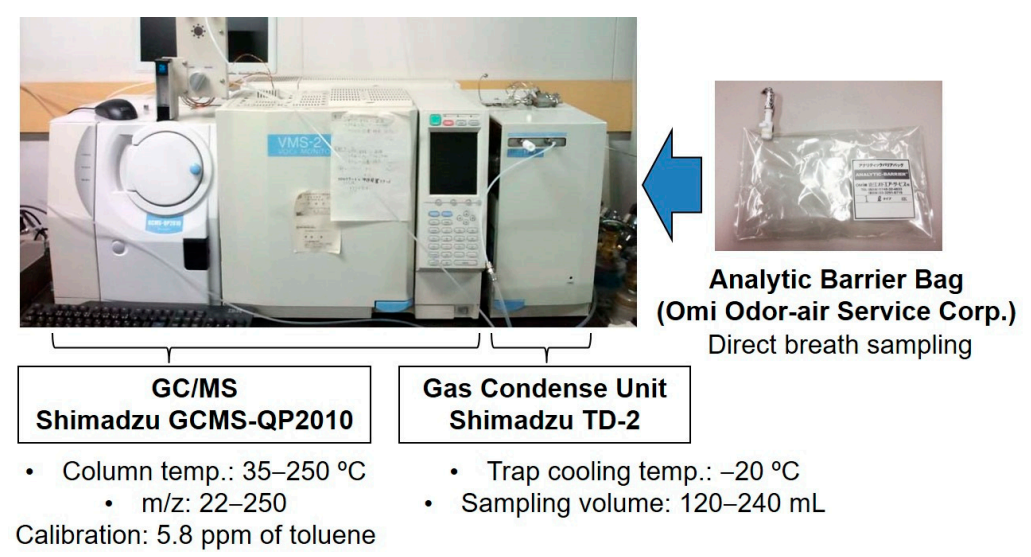

Figure 1. Breath sampling and gas analysis by GC/MS.

We detected 63 VOCs. Among them, three VOCs may come from cancer treatment drugs and 40 VOCs were present at low concentrations, close to the detection limit of GC/MS. We deleted these 43 VOCs and examined the SVM diagnosis using the remaining 20 VOCs (Table 1).

Table 1. Selected volatile organic compounds (VOCs) for the computer-assisted diagnostic analysis.

\begin{tabular}{ccccc}
\hline Butane $^{\ddagger \ddagger}$ & $\mathrm{CH}_{3} \mathrm{CN}^{\dagger, \ddagger}$ & $\mathrm{CHCl}_{3}{ }^{\dagger, \ddagger}$ & Methanol $^{\dagger}$ & Acetone $^{\ddagger}$ \\
\hline $\mathrm{CHN} \ddagger$ & Ethanol & 1-Propanol & 2-Propanol & $\mathrm{C}_{8} \mathrm{H}_{16}$ \\
Isoprene & Dichlorobenzene & $\mathrm{C}_{8} \mathrm{H}_{17} \mathrm{OH}$ & Xylene & Methylcyclohexane \\
Toluene & $\mathrm{C}_{2} \mathrm{H}_{3} \mathrm{CN}$ & Limonene & Nonanal & Unknown ${ }^{1}$ \\
\hline
\end{tabular}

${ }^{\dagger}$ Wilcoxon test: $p<0.05 ;{ }^{\ddagger}$ Kolmogorov-Smirnov test: $p<0.05 ;{ }^{1}$ this VOC could not be identified.




\subsection{Data Sets}

As listed in Table 1, many of the VOCs have no significant differences between cancer and healthy samples, and the concentration distributions of the VOCs (nine VOCs are selected and shown in Figure 2) show unclear boundaries between the cancer and healthy control samples. Some of the lung cancer samples contained higher concentrations of VOCs than the healthy samples; however, there was a wide overlap of the types of VOCs found in each sample. This suggests that it is quite difficult to diagnose lung cancer using a single VOC; thus, diagnosis using multiple VOCs is necessary.

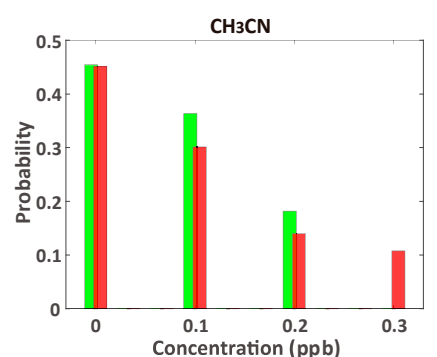

(a)

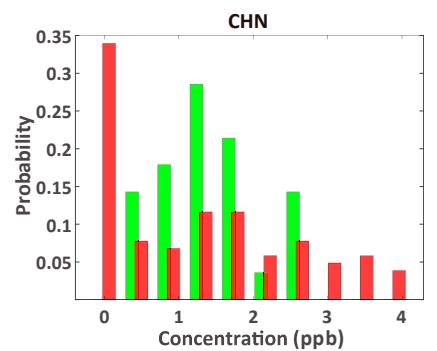

(d)

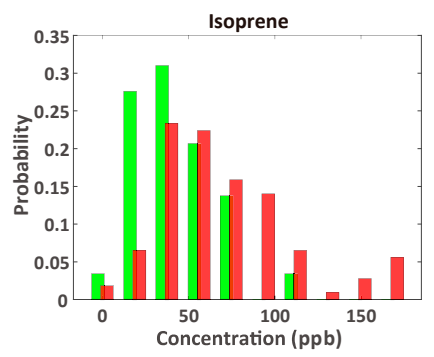

(g)

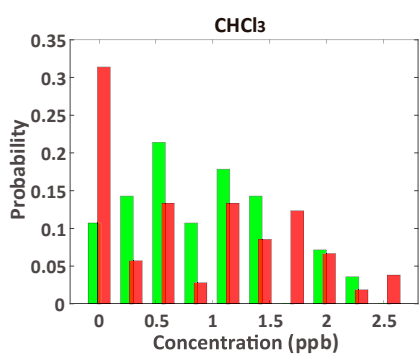

(b)

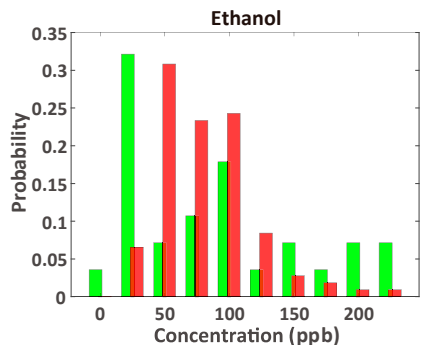

(e)

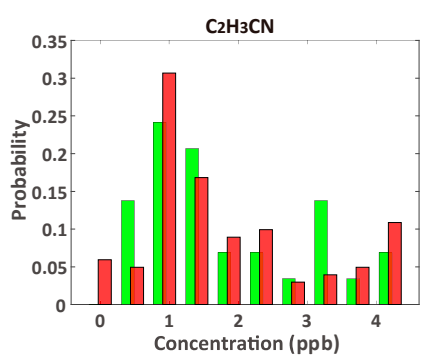

(h)

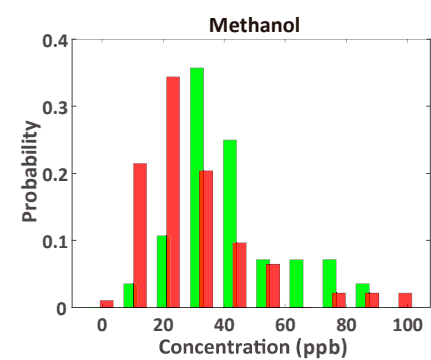

(c)

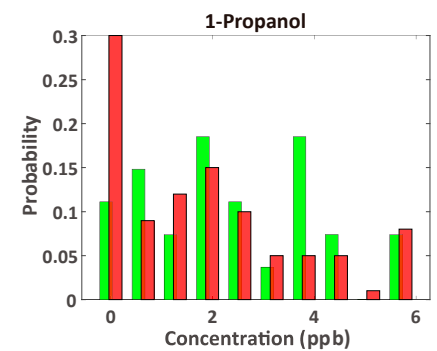

(f)

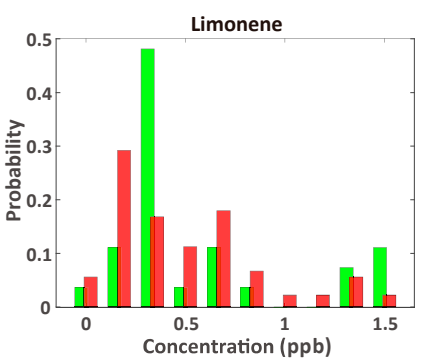

(i)

Figure 2. Comparison of VOC concentration distributions from lung cancer (red, $n=107$ ) and healthy (green, $n=29$ ) controls' breath; (a) $\mathrm{CH}_{3} \mathrm{CN}$; (b) $\mathrm{CHCl}_{3}$; (c) methanol; (d) $\mathrm{CHN}$; (e) ethanol; (f) 1-propanol; (g) isoprene; (h) $\mathrm{C}_{2} \mathrm{H}_{3} \mathrm{CN}$; and (i) limonene. The VOCs in (a-e) show significant differences between samples, while those in (f-i) do not show significant differences (Table 1). The distributions of the remaining 11 VOCs are shown in the Supplementary Information (Figure S1).

There are $1,048,575\left(=\sum_{i=120}^{20} C_{i}\right.$, where ${ }_{n} C_{k}$ represents $k$-combinations of $n$ elements $)$ VOC combinations of the 20 VOCs listed in Table 1. We applied nonlinear SVM diagnosis to each of the combinations and evaluated their accuracy levels, as described below. A VOC that has no contribution toward improving the diagnostic accuracy should be removed from the data set even if it has a large contribution to the principal component space, and vice versa. In addition, reducing the number of possible VOCs is helpful for designing a portable VOC detector.

The imbalanced sample numbers in the VOC data set (lung cancer patients: 107; healthy individuals: 29) likely cause an inappropriate classification. To complete the sample numbers, we introduced a synthetic minority oversampling technique [34-36]. One original sample (healthy 
control in our case) was randomly chosen, and two virtual samples were interpolated at a random point between the chosen sample and the two samples that are nearest to the chosen one (case of nearest number $k=2$; Figure 3). By repeating this process, we provided 107 healthy control samples.

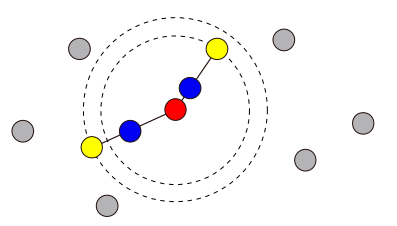

Figure 3. Schematic illustrating the oversampling technique to obtain the same number of healthy control samples to that of the lung cancer patients. After one sample (red) is randomly chosen, two samples (blue) are randomly interpolated on the lines between the chosen sample and the two nearest samples (yellow).

\subsection{SVM Classifier}

SVM is an algorithm that determines a flat classification boundary between two-class data sets. The concentration distribution of the selected VOCs is broad and shows unclear boundaries between the cancer and healthy samples; thus, it is difficult to clearly classify the VOC samples using linear SVM [22]. We introduced a nonlinear SVM [37] with a Gaussian kernel function, which is widely used for classifying biological data sets (e.g., microarray gene expressions [38-40], DNA fragments [41], and cell shapes [42]). In general, the data point coordinates are transformed to a higher dimensional coordinate space, where SVM can draw a flat boundary between the transformed two-class data sets (Figure 4). The coordinate transformation is characterized by the kernel function. We used a Gaussian kernel function, $\exp \left(-\left\|\mathbf{x}_{1}-\mathbf{x}_{2}\right\|^{2} / 2 \sigma^{2}\right)$, where $\mathbf{x}_{1}$ and $\mathbf{x}_{2}$ represent normalized VOC data points and $\sigma$ is a parameter that scales the distance between the points. Another parameter, $C$, regulates the penalty for misclassification. Here, we set $\sigma=1.5$ and $C=1000$ to reduce the number of data points that determine the classification boundary (support vectors), by which SVM can avoid overfitting the dataset. All computations were performed using SVM functions (svmtrain, svmclassify) within the Statistics and Machine Learning Toolbox of MATLAB (MathWorks).

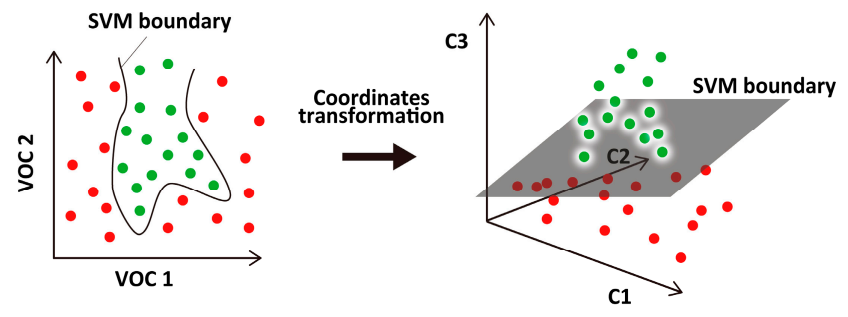

(a)

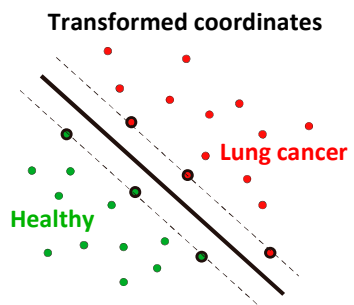

(b)

Figure 4. Schematic illustrating nonlinear support vector machine (SVM). (a) The two-class data set is composed of two VOCs (VOC 1 and VOC 2; left panel), which are transformed into a different coordinate space (right panel) where the dataset can be classified by a flat boundary; (b) The SVM boundary (thick line) is determined using data points called support vectors (thick circles). The number of support vectors should be small to avoid overfitting the data points.

\subsection{Evaluation of Classification Accuracy}

We introduced the leave-one-out cross-validation (LOOCV) method, which is widely used in biology $[43,44]$ and breath gas analysis $[5,14,45,46]$, to evaluate the capability of the SVM diagnosis for the given data set. In LOOCV, one data point is left out of the data set to evaluate the accuracy of the diagnosis, while the remaining data points are used to train the classifier. Then, the left-out data point 
is diagnosed by the trained classifier (Figure 5). This process is repeated for each sample to compute the true positive rate $(\mathrm{TPR}=T P /(T P+F N))$, true negative rate $(\mathrm{TNR}=T N / T N+F P)$, and accuracy $(\mathrm{ACC}=(T P+T N) /(T P+F N+T N+F P))$, where 29 healthy controls were used as true negative samples. These values equal $100 \%$ if a completely accurate diagnosis is achieved. We applied LOOCV to all of the VOC combinations to screen the effective combinations for cancer diagnosis.

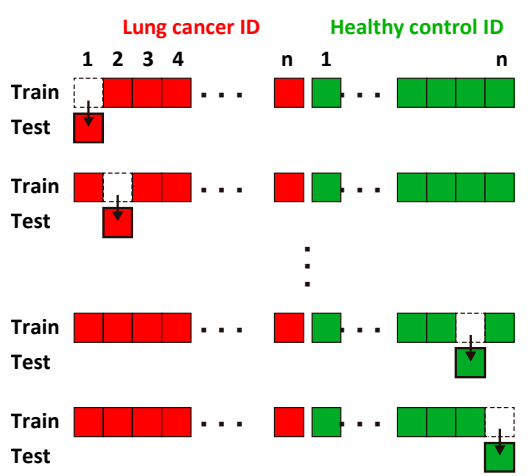

Figure 5. Schematic illustrating the leave-one-out cross-validation (LOOCV) procedure. A data point is repeatedly exchanged to categorize the training and testing data set.

\section{Results and Discussion}

\subsection{Optimal Number of VOCs for Classification}

The diagnostic accuracy using the original data set $(n=107$ for lung cancer patients and $n=29$ for healthy individuals) and oversampled healthy samples $(n=78)$ depends on the number of VOCs trained by the SVM classifier, as summarized in Figure 6a. The accuracy increases as more VOCs are included, and the maximum accuracy is achieved using 9 or 10 VOCs, while the best TPR is saturated even for one VOC, and the best TNR decreases above 4 VOCs. In contrast, the numbers of corresponding support vectors of the ACC and TPR classification are the lowest (18.7\% of the data points) when there are 5 trained VOCs, and that of TNR reaches almost bottom for 4 VOCs (Figure $6 \mathrm{~b}$ ). These results suggest that, without overfitting, 5 VOCs are sufficient for $89.0 \%$ diagnostic accuracy, and that the 95\% TPR- and 89\% TNR-based diagnoses are possible when using 5 and 4 VOCs, respectively.

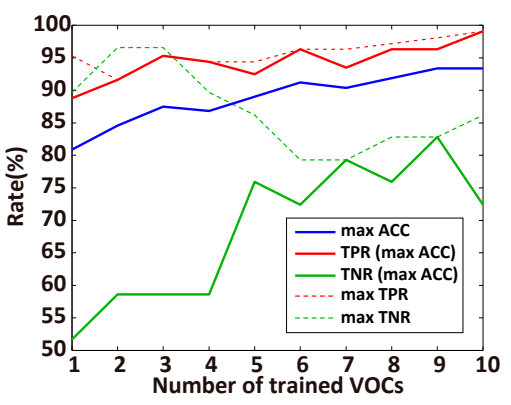

(a)

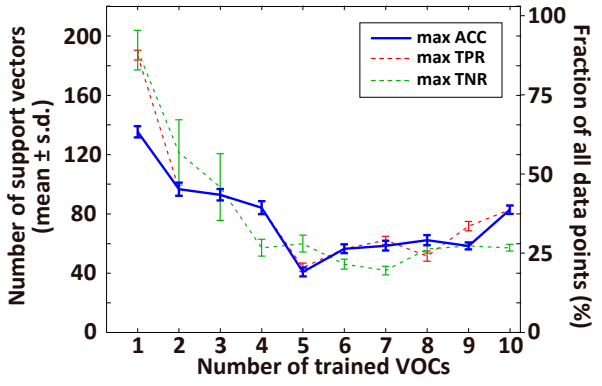

(b)

Figure 6. Dependency of the performance of SVM diagnosis on the number of trained VOCs of the data set (lung cancer patients, $n=107$; healthy individuals, $n=29$, oversampling healthy samples, $n=78$ ). (a) Best accuracy (ACC, blue line) with the corresponding true positive rate (TPR, solid red line) and true negative rate (TNR, solid green line) within all combinations of each number of trained VOCs (from 1 to 10). The dashed red and green lines represent the best TPR and TNR, respectively; (b) The number of support vectors that are used in the classifier in (a) for the best ACC (blue), TPR (red), and TNR (green). Left and right y-axes represent the actual number of data points and fraction of all data points, respectively. 


\subsection{Effective VOC Combinations for Diagnosing Lung Cancer}

We determined effective VOC combinations for diagnosing lung cancer with high values for ACC (Table 2), TPR (Table 3), and TNR (Table 4) by fixing the number of trained VOCs at the value that provided a small number of support vectors ( $n=5$ for ACC, $n=5$ for TPR, and $n=4$ for TNR; Figure 6b). The VOC combinations are sorted by ACC, TPR, and TNR. The most important VOC combinations could not be determined because the differences between the rates in these tables are not large, and the VOC concentrations may contain noises caused by the sensor or sampling process. However, certain VOCs were common in each combination while some VOCs (e.g., nonanal and toluene) were rarely used for diagnosis.

Table 2. Top 10 VOC combinations sorted by ACC (\%) (5 VOCs were trained, MC = methylcyclohexane; boldface: most frequent VOC).

\begin{tabular}{|c|c|c|c|c|c|c|c|c|c|c|}
\hline Rank & 1 & 2 & 2 & 2 & 2 & 6 & 6 & 6 & 9 & 9 \\
\hline ACC & 89.0 & 88.2 & 88.2 & 88.2 & 88.2 & 86.8 & 86.8 & 86.8 & 86.0 & 86.0 \\
\hline TPR & 92.5 & 91.6 & 93.5 & 91.6 & 92.5 & 91.6 & 89.7 & 92.5 & 91.6 & 87.9 \\
\hline TNR & 75.9 & 75.9 & 69.0 & 75.9 & 72.4 & 69.0 & 75.9 & 65.5 & 65.5 & 79.3 \\
\hline VOCs & $\begin{array}{c}\mathrm{CHN} \\
\text { Methanol } \\
\mathrm{CH}_{3} \mathrm{CN} \\
\text { Isoprene } \\
\text { 1-Propanol }\end{array}$ & $\begin{array}{c}\mathrm{CHN} \\
\mathrm{CH}_{3} \mathrm{CN} \\
\mathrm{C}_{2} \mathrm{H}_{3} \mathrm{CN} \\
\text { Isoprene } \\
\mathrm{CHCl}_{3}\end{array}$ & $\begin{array}{c}\text { Methanol } \\
\text { Acetone } \\
\mathrm{C}_{2} \mathrm{H}_{3} \mathrm{CN} \\
\text { Isoprene } \\
\text { 1-Propanol }\end{array}$ & $\begin{array}{l}\text { Methanol } \\
\text { Isoprene } \\
\text { Xylene } \\
\text { Unknown-1 } \\
\mathrm{C}_{8} \mathrm{H}_{17} \mathrm{OH}\end{array}$ & $\begin{array}{c}\text { Butane } \\
\mathrm{CH}_{3} \mathrm{CN} \\
\text { Isoprene } \\
\text { 1-Propanol } \\
\text { Xylene }\end{array}$ & $\begin{array}{c}\mathrm{CHN} \\
\text { Methanol } \\
\mathrm{CH}_{3} \mathrm{CN} \\
\text { 1-Propanol } \\
\text { MC }\end{array}$ & $\begin{array}{c}\mathrm{CHN} \\
\text { Butane } \\
\mathrm{CH}_{3} \mathrm{CN} \\
\text { Isoprene } \\
\mathrm{CHCl}_{3}\end{array}$ & $\begin{array}{l}\mathrm{C}_{2} \mathrm{H}_{3} \mathrm{CN} \\
\text { Isoprene } \\
\text { 1-Propanol } \\
\text { Unknown-1 } \\
\mathrm{C}_{8} \mathrm{H}_{17} \mathrm{OH}\end{array}$ & $\begin{array}{c}\text { CHN } \\
\text { Ethanol } \\
\text { Isoprene } \\
\text { 1-Propanol } \\
\text { Toluene }\end{array}$ & $\begin{array}{c}\mathrm{CHN} \\
\mathrm{CH}_{3} \mathrm{CN} \\
\text { Isoprene } \\
\mathrm{CHCl}_{3} \\
\text { Xylene }\end{array}$ \\
\hline
\end{tabular}

Table 3. Top 10 VOC combinations sorted by TPR (\%) (5 VOCs were trained, MC = methylcyclohexane; boldface: most frequent VOC).

\begin{tabular}{|c|c|c|c|c|c|c|c|c|c|c|}
\hline Rank & 1 & 2 & 3 & 3 & 3 & 3 & 3 & 3 & 3 & 10 \\
\hline ACC & 84.6 & 88.2 & 86.0 & 89.0 & 84.6 & 88.2 & 85.3 & 85.3 & 86.8 & 86.8 \\
\hline TNR & 48.3 & 69.0 & 62.1 & 75.9 & 55.2 & 72.4 & 58.6 & 58.6 & 65.5 & 69.0 \\
\hline \multirow{4}{*}{ VOCs } & Ethanol & Acetone & $\mathrm{CH}_{3} \mathrm{CN}$ & Methanol & Ethanol & $\mathrm{CH}_{3} \mathrm{CN}$ & $\mathrm{CH}_{3} \mathrm{CN}$ & $\mathrm{CH}_{3} \mathrm{CN}$ & Isoprene & Methanol \\
\hline & Acetone & $\mathrm{C}_{2} \mathrm{H}_{3} \mathrm{CN}$ & $\mathrm{C}_{2} \mathrm{H}_{3} \mathrm{CN}$ & $\mathrm{CH}_{3} \mathrm{CN}$ & $\mathrm{C}_{2} \mathrm{H}_{3} \mathrm{CN}$ & Isoprene & Acetone & MC & 1-Propanol & $\mathrm{CH}_{3} \mathrm{CN}$ \\
\hline & $\mathrm{C}_{2} \mathrm{H}_{3} \mathrm{CN}$ & Isoprene & Isoprene & Isoprene & 1-Propanol & 1-Propanol & 2-Propanol & Unknown-1 & Unknown-1 & 1-Propanol \\
\hline & Toluene & 1-Propanol & 1-Propanol & 1-Propanol & $\mathrm{CHCl}_{3}$ & Xylene & $\mathrm{C}_{2} \mathrm{H}_{3} \mathrm{CN}$ & $\mathrm{C}_{8} \mathrm{H}_{17} \mathrm{OH}$ & $\mathrm{C}_{8} \mathrm{H}_{17} \mathrm{OH}$ & MC \\
\hline
\end{tabular}

Table 4. Top 10 VOC combinations sorted by TNR (\%) (4 VOCs were trained, MC = methylcyclohexane; boldface: most frequent VOCs).

\begin{tabular}{|c|c|c|c|c|c|c|c|c|c|c|}
\hline Rank & 1 & 2 & 2 & 2 & 5 & 5 & 5 & 5 & 5 & 10 \\
\hline ACC & 84.6 & 89.0 & 88.2 & 84.6 & 88.2 & 85.3 & 86.0 & 85.3 & 86.8 & 86.8 \\
\hline TNR & 89.7 & 86.2 & 86.2 & 86.2 & 82.8 & 82.8 & 82.8 & 82.8 & 82.8 & 79.3 \\
\hline
\end{tabular}

The variation of VOC combinations in the top diagnosis above was probably caused by the noise in the detected concentration, cancer type, or cancer stage. We extracted the VOCs that were frequently present in the top 10 combinations (Table 5). The results show that: (1) $\mathrm{CH}_{3} \mathrm{CN}$ and isoprene are commonly used for all diagnoses; (2) the frequently used combination in ACC is the same as the best combination in Table 2; (3) 1-propanol, $\mathrm{C}_{2} \mathrm{H}_{3} \mathrm{CN}$, and ethanol are specific to the TPR-based diagnosis; (4) the frequently used combination in TPR is same as the third combination in Table 3; (5) CHN, $\mathrm{CH}_{3} \mathrm{CN}$, and methanol are specific to the TNR-based diagnosis; (6) the frequently used combination in TNR, except for methanol, is the same as the second combination in Table 5; and (7) the group of VOCs in the ACC-based diagnosis ("Top ACC" in Table 5) contains a mixture of VOCs from the TPRand TNR-based diagnoses and justifies the definition of ACC (i.e., the indicator merging TPR and TNR). If the eight VOCs listed in Table 5 (two from ACC, three from TPR, and three from TNR) were used, the SVM diagnosis would show a performance of $84.6 \%$ for ACC, $91.6 \%$ for TPR, and $58.6 \%$ for TNR, with $54.2 \pm 5.47$ for the number of support vectors. This is not a particularly bad performance, 
but TNR, in particular, would provide a low performance. This is probably caused by the small number of original healthy controls. The extracted VOCs from the VOCs in Table 1 are different from the result of our previous study [33], where the selection of target VOCs is different.

Table 5. VOCs that are frequently used in the top 10 ACC (Table 2), TPR (Table 3), and TNR (Table 4) combinations. The VOCs written in boldface are the same as those in Tables 2-4 and represent the VOCs that are used most frequently in the ACC-, TPR-, or TNR-based diagnoses. VOCs commonly used in every diagnosis and those specifically used for TPR- and TNR-based diagnoses are colored by blue, red, and green, respectively.

\begin{tabular}{ccc|ccc|ccc}
\hline & ACC & \multicolumn{3}{c|}{ TPR } & \multicolumn{3}{c}{ TNR } \\
\hline Rank & VOC & Count & Rank & VOC & Count & Rank & VOC & Count \\
\hline 1 & Isoprene & 9 & 1 & 1-Propanol & 7 & 1 & CHN & 7 \\
\hline 2 & $\mathrm{CHN}$ & 6 & 2 & $\mathrm{C}_{2} \mathrm{H}_{3} \mathrm{CN}$ & 6 & 1 & $\mathbf{C H}_{3} \mathbf{C N}$ & 7 \\
\hline 2 & 1-Propanol & 6 & 2 & $\mathrm{CH}_{3} \mathrm{CN}$ & 6 & 3 & Methanol & 5 \\
\hline 2 & $\mathrm{CH}_{3} \mathrm{CN}$ & 6 & 4 & Ethanol & 5 & 3 & Isoprene & 5 \\
\hline 5 & Methanol & 4 & 4 & Isoprene & 5 & 5 & $\mathrm{CHCl}_{3}$ & 3 \\
\hline
\end{tabular}

Furthermore, to examine the discriminability between the cancer and healthy samples, the scatter diagrams for six combinations of three VOCs in Table 5 were plotted on 3D coordinates (Figure 7). The results represent much smaller overlaps between the lung cancer and healthy groups than the 1D representation in Figure 2, and suggest a high discriminability between cancer patients and healthy subjects using the VOC combination rather than single VOCs.
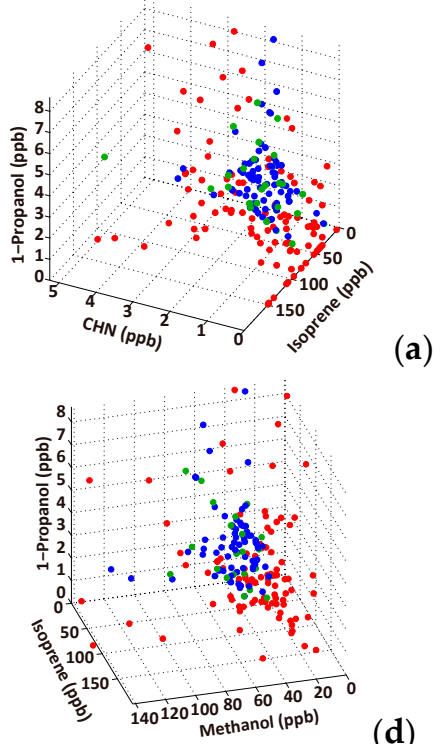

(d)

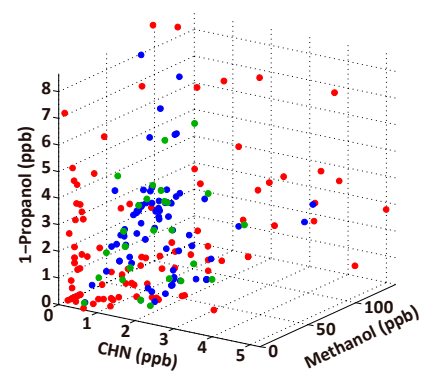

(b)
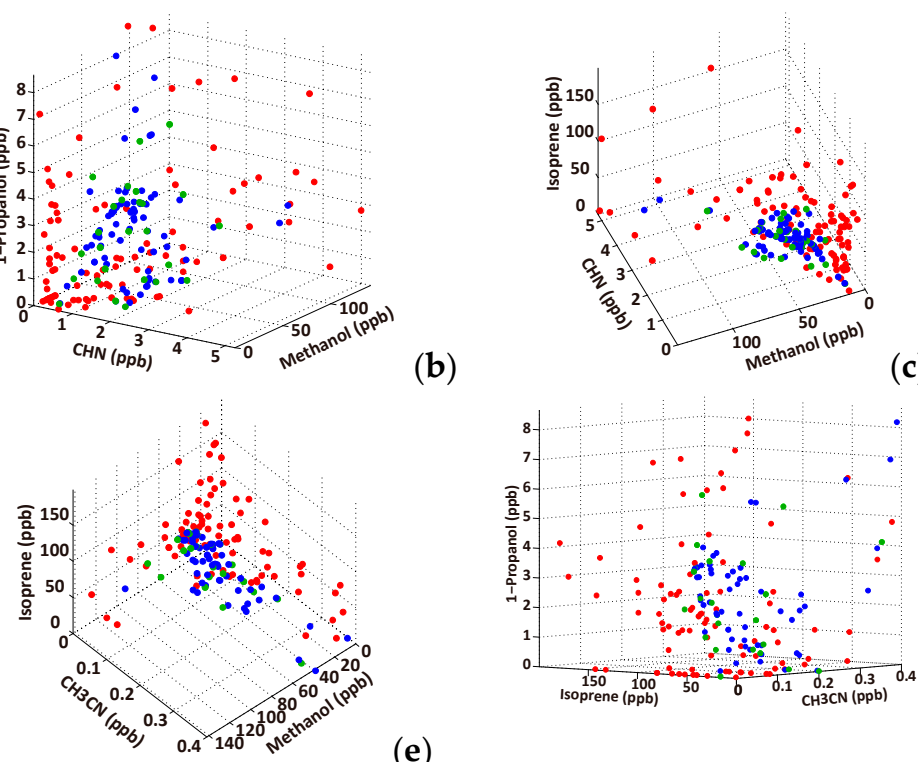

(f)

Figure 7. VOC distributions on a 3D representation for the list of top accuracy combinations in Table 5. $\mathrm{CHN}$, isoprene, 1-propanol (a); $\mathrm{CHN}$, methanol, 1-propanol (b); $\mathrm{CHN}$, methanol, isoprene (c); isoprene, methanol, 1-propanol (d); $\mathrm{CH}_{3} \mathrm{CN}$, methanol, isoprene (e); and isoprene, $\mathrm{CH}_{3} \mathrm{CN}$, 1-propanol (f). The red and green circles represent lung cancer patients and healthy controls, respectively, and the blue circles indicate the oversampling data. The oversampling data are more widely spread than the original healthy samples in this range because some of the healthy samples exist outside of the axis range.

\subsection{Correlation between Cancer Stage and Distance from the Classification Boundary}

Data points near the classification boundary contain a property of each class because SVM provides a boundary between the two-class data points. In other words, the data points that are far from the boundary have the specific property of their class. In the SVM diagnosis, the data samples of 
low cancer stages are located near the boundary and those of high stages are far from the boundary (Figure 8a). Such a distance-based feature extraction has been theoretically studied $[47,48]$ and applied to MRI images of the brain [49]. Thus, we computed the distances of the cancer samples from the boundary using the best VOC combination in the TPR rank with the LOO fashion; the test sample distances are computed by the classifier developed by the remaining learning samples. The higher cancer stage samples are located relatively far from the boundary (Figure $8 \mathrm{~b}$ ). This suggests that the SVM diagnosis could be used for estimating the cancer stage of a patient. The first-stage patients have relatively long distances. This may be caused by noise in VOCs, mislabeling of stage, or nonlinear transformation of the VOCs near the boundary.

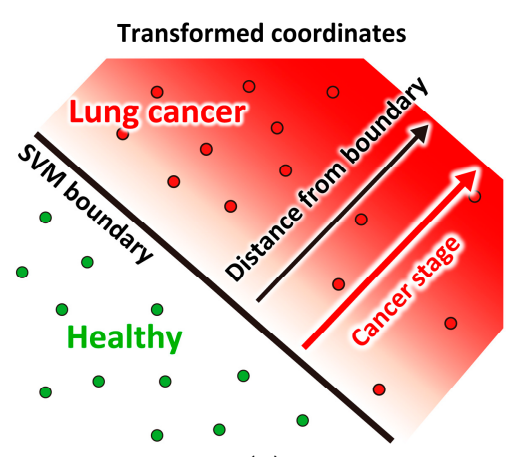

(a)

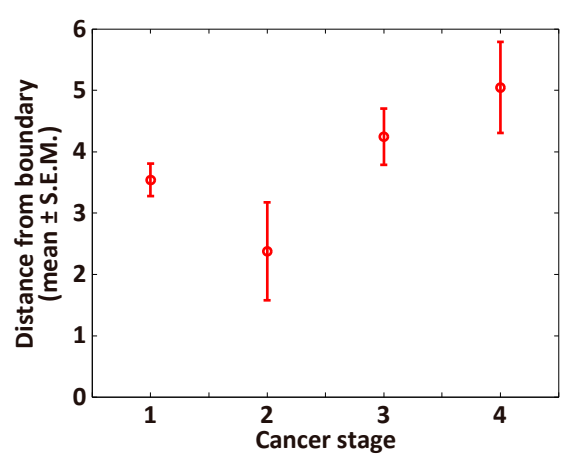

(b)

Figure 8. (a) Schematic illustration of the hypothesis that the cancer stage correlates with distance from the SVM boundary in the transformed coordinates space; (b) The $y$-axis indicates the distance from the SVM boundary. The learning VOC combination of the best TPR in Table 3 (butane, ethanol, acetone, $\mathrm{C}_{2} \mathrm{H}_{3} \mathrm{CN}$, and toluene) was used for computing the test sample distance.

\section{Summary and Conclusions}

We have applied nonlinear SVM classification to the detection of VOCs for lung cancer diagnosis with leave-one-out cross-validation, and have determined the optimal VOC patterns for the diagnosis. Optimal combinations of VOCs depend on ACC, TPR, or TNR (Tables 2-4). The TPR- and TNR-based optimal combinations are useful for biologically investigating why cancer patients and healthy people are characterized by these VOCs. The ACC-based optimal combinations will be used for diagnosing subjects. The TPR-based diagnosis is better for avoiding a risk of false negative. The efficient strategy is to develop a diagnosis tool based on the ACC-based diagnosis while the TPR-based diagnoses is used in hospitals because improving the ACC diagnosis also improves the TPR diagnosis.

The TNR results were lower than that for TPR for all VOC combinations. This is possibly caused by the oversampling of the healthy controls and will be improved by collecting VOCs from more healthy individuals. For the correlation between the SVM distance and cancer stage, a possible alternative application would be to classify samples into 5 classes (stages $1-4$ and healthy) by SVM. This work may be performed in the future, because we cannot currently obtain a high accuracy using a multiclass SVM.

The optimal VOC set was selected based on the VOC concentrations, each of which was detected by the same GC/MS. There is little quantitative variation added by the GC/MS. If we use a different GC/MS that has different VOC sensitivities, some VOCs will have different measured concentrations. Even in this case, the SVM diagnosis will select effective VOC combinations similar to those in this work, because the VOC concentrations are normalized in the SVM; a relative concentration correlation between samples is important for classification. However, this argument does not hold, and different VOC combinations are possibly selected, in the case that the detected VOCs differ depending on the GC/MS because of VOC sensitivity.

We showed that a diagnosis with $89.0 \%$ accuracy can be performed using five VOCs. This highly efficient SVM classification will be integrated into the prototype breath analyzer for lung cancer 
screening utilizing double GC columns and sensors [33], and a new breath test in Aichi Cancer Center is going to start. It must be confirmed that the selected VOCs are also optimal sets when we diagnose with the prototype analyzer specialized to these optimal VOCs in future.

We promote this integration and prototype analyzer, expecting that the SVM classifier can be used for the further development of a desktop GC-sensor analysis system for lung cancer. Furthermore, if the precise VOC composition of five VOC mixtures is measured, the cancer stage can be predicted, as it is correlated with the distance of a cancer sample from the SVM classification boundary.

Supplementary Materials: The following are available online at http://www.mdpi.com/1424-8220/17/2/287/ s1, Figure S1: VOC concentration distributions from lung cancer (red, $n=107$ ) and healthy (green, $n=29$ ) controls' breath.

Acknowledgments: This work was supported by the Knowledge Hub Aichi (the priority research project: P3-G3-S1) of Aichi Prefecture and Special Research Aid of the President of Aichi Prefectural University, Japan. The authors also thank Profs. Takaharu Kondo (Chubu University, Japan), Kazushi Ikeda (Nara Institute of Science and Technology, Japan), Junichiro Yoshimoto (Nara Institute of Science and Technology, Japan), and Thomas N. Sato (ERATO Sato Live Bio-Forecasting Project, Japan) for their comments regarding the breath analysis.

Author Contributions: Y.S. designed the data analysis and wrote the paper; Y.K. and H.T. developed the MATLAB code; T.H. collected breath gases; K.S. designed the study; T.I. performed the gas analysis experiments; T.A. contributed the experimental methods; W.S. conceived of and designed the study of breath analysis, and wrote the paper. All authors discussed the results and the implications of this manuscript.

Conflicts of Interest: The authors declare no conflict of interest.

\section{References}

1. Gordon, S.; Szidon, J.; Krotoszynski, B.; Gibbons, R.; O’Neill, H. Volatile organic compounds in exhaled air from patients with lung cancer. Clin. Chem. 1985, 31, 1278-1282. [PubMed]

2. Kharitonov, S.A.; Barnes, P.J. Biomarkers of some pulmonary diseases in exhaled breath. Biomarkers 2002, 7, 1-32. [CrossRef] [PubMed]

3. Bach, P.B.; Kelley, M.J.; Tate, R.C.; McCrory, D.C. Screening for lung cancer: A review of the current literature. Chest 2003, 123, 72S-82S. [CrossRef] [PubMed]

4. Corazza, G.; Menozzi, M.; Strocchi, A.; Rasciti, L.; Vaira, D.; Lecchini, R.; Avanzini, P.; Chezzi, C.; Gasbarrini, G. The diagnosis of small bowel bacterial overgrowth. Reliability of jejunal culture and inadequacy of breath hydrogen testing. Gastroenterology 1990, 98, 302-309. [CrossRef]

5. Phillips, M.; Gleeson, K.; Hughes, J.M.B.; Greenberg, J.; Cataneo, R.N.; Baker, L.; McVay, W.P. Volatile organic compounds in breath as markers of lung cancer: A cross-sectional study. Lancet 1999, 353, 1930-1933. [CrossRef]

6. Amann, A.; Poupart, G.; Telser, S.; Ledochowski, M.; Schmid, A.; Mechtcheriakov, S. Applications of breath gas analysis in medicine. Int. J. Mass Spectrom. 2004, 239, 227-233. [CrossRef]

7. Amann, A.; Smith, D. Breath Analysis for Clinical Diagnosis and Therapeutic Monitoring: (With CD-ROM); World Scientific: Singapore, 2005.

8. Machado, R.F.; Laskowski, D.; Deffenderfer, O.; Burch, T.; Zheng, S.; Mazzone, P.J.; Mekhail, T.; Jennings, C.; Stoller, J.K.; Pyle, J. Detection of lung cancer by sensor array analyses of exhaled breath. Am. J. Respir. Crit. Care Med. 2005, 171, 1286-1291. [CrossRef] [PubMed]

9. Wehinger, A.; Schmid, A.; Mechtcheriakov, S.; Ledochowski, M.; Grabmer, C.; Gastl, G.A.; Amann, A. Lung cancer detection by proton transfer reaction mass-spectrometric analysis of human breath gas. Int. J. Mass Spectrom. 2007, 265, 49-59. [CrossRef]

10. Mazzone, P.J. Analysis of volatile organic compounds in the exhaled breath for the diagnosis of lung cancer. J. Thorac. Oncol. 2008, 3, 774-780. [CrossRef] [PubMed]

11. Fuchs, P.; Loeseken, C.; Schubert, J.K.; Miekisch, W. Breath gas aldehydes as biomarkers of lung cancer. Int. J. Cancer 2010, 126, 2663-2670. [CrossRef] [PubMed]

12. Lourenco, C.; Turner, C. Breath analysis in disease diagnosis: Methodological considerations and applications. Metabolites 2014, 4, 465-498. [CrossRef] [PubMed] 
13. Phillips, M.; Cataneo, R.N.; Cummin, A.R.; Gagliardi, A.J.; Gleeson, K.; Greenberg, J.; Maxfield, R.A.; Rom, W.N. Detection of lung cancer with volatile markers in the breath. Chest J. 2003, 123, 2115-2123. [CrossRef]

14. Di Natale, C.; Macagnano, A.; Martinelli, E.; Paolesse, R.; D'Arcangelo, G.; Roscioni, C.; Finazzi-Agrò, A.; D'Amico, A. Lung cancer identification by the analysis of breath by means of an array of non-selective gas sensors. Biosens. Bioelectron. 2003, 18, 1209-1218. [CrossRef]

15. Phillips, M.; Altorki, N.; Austin, J.H.; Cameron, R.B.; Cataneo, R.N.; Greenberg, J.; Kloss, R.; Maxfield, R.A.; Munawar, M.I.; Pass, H.I. Prediction of lung cancer using volatile biomarkers in breath. Cancer Biomark. 2007, 3, 95-109. [CrossRef] [PubMed]

16. Peng, G.; Tisch, U.; Adams, O.; Hakim, M.; Shehada, N.; Broza, Y.Y.; Billan, S.; Abdah-Bortnyak, R.; Kuten, A.; Haick, H. Diagnosing lung cancer in exhaled breath using gold nanoparticles. Nat. Nanotechnol. 2009, 4, 669-673. [CrossRef] [PubMed]

17. Dragonieri, S.; Annema, J.T.; Schot, R.; van der Schee, M.P.; Spanevello, A.; Carratú, P.; Resta, O.; Rabe, K.F.; Sterk, P.J. An electronic nose in the discrimination of patients with non-small cell lung cancer and COPD. Lung Cancer 2009, 64, 166-170. [CrossRef] [PubMed]

18. Mazzone, P.J.; Wang, X.-F.; Xu, Y.; Mekhail, T.; Beukemann, M.C.; Na, J.; Kemling, J.W.; Suslick, K.S.; Sasidhar, M. Exhaled breath analysis with a colorimetric sensor array for the identification and characterization of lung cancer. J. Thorac. Oncol. 2012, 7, 137-142. [CrossRef] [PubMed]

19. Pennazza, G.; Santonico, M.; Martinelli, E.; D'Amico, A.; Di Natale, C. Interpretation of exhaled volatile organic compounds. In Exhaled Biomarkers; European Respiratory Society: Lausanne, Switzerland, 2010.

20. Mazzone, P.J.; Hammel, J.; Dweik, R.; Na, J.; Czich, C.; Laskowski, D.; Mekhail, T. Diagnosis of lung cancer by the analysis of exhaled breath with a colorimetric sensor array. Thorax 2007, 62, 565-568. [CrossRef] [PubMed]

21. Phillips, M.; Altorki, N.; Austin, J.H.; Cameron, R.B.; Cataneo, R.N.; Kloss, R.; Maxfield, R.A.; Munawar, M.I.; Pass, H.I.; Rashid, A. Detection of lung cancer using weighted digital analysis of breath biomarkers. Clin. Chim. Acta 2008, 393, 76-84. [CrossRef] [PubMed]

22. Vapnik, V.; Lerner, A. Pattern recognition using generalized portrait method. Autom. Remote Control 1963, 24, 774-780.

23. Ruan, S.; Lebonvallet, S.; Merabet, A.; Constans, J.-M. Tumor segmentation from a multispectral MRI images by using support vector machine classification. In Proceedings of the 2007 4th IEEE International Symposium on Biomedical Imaging: From Nano to Macro, Arlington, VA, USA, 12-15 April 2007; pp. 1236-1239.

24. Zacharaki, E.I.; Wang, S.; Chawla, S.; Soo Yoo, D.; Wolf, R.; Melhem, E.R.; Davatzikos, C. Classification of brain tumor type and grade using MRI texture and shape in a machine learning scheme. Magn. Reson. Med. 2009, 62, 1609-1618. [CrossRef] [PubMed]

25. Klöppel, S.; Stonnington, C.M.; Chu, C.; Draganski, B.; Scahill, R.I.; Rohrer, J.D.; Fox, N.C.; Jack, C.R.; Ashburner, J.; Frackowiak, R.S. Automatic classification of MR scans in Alzheimer's disease. Brain 2008, 131, 681-689. [CrossRef] [PubMed]

26. Ortiz, A.; Górriz, J.M.; Ramírez, J.; Martínez-Murcia, F.J. LVQ-SVM based CAD tool applied to structural MRI for the diagnosis of the Alzheimer's disease. Pattern Recognit. Lett. 2013, 34, 1725-1733. [CrossRef]

27. Marquand, A.F.; Mourão-Miranda, J.; Brammer, M.J.; Cleare, A.J.; Fu, C.H. Neuroanatomy of verbal working memory as a diagnostic biomarker for depression. Neuroreport 2008, 19, 1507-1511. [CrossRef] [PubMed]

28. Nouretdinov, I.; Costafreda, S.G.; Gammerman, A.; Chervonenkis, A.; Vovk, V.; Vapnik, V.; Fu, C.H. Machine learning classification with confidence: Application of transductive conformal predictors to MRI-based diagnostic and prognostic markers in depression. Neuroimage 2011, 56, 809-813. [CrossRef] [PubMed]

29. Barash, O.; Peled, N.; Tisch, U.; Bunn, P.A., Jr.; Hirsch, F.R.; Haick, H. Classification of lung cancer histology by gold nanoparticle sensors. Nanomedicine 2012, 8, 580-589. [CrossRef] [PubMed]

30. Van Berkel, J.J.; Dallinga, J.W.; Moller, G.M.; Godschalk, R.W.; Moonen, E.; Wouters, E.F.; van Schooten, F.J. Development of accurate classification method based on the analysis of volatile organic compounds from human exhaled air. J. Chromatogr. B 2008, 861, 101-107. [CrossRef] [PubMed]

31. Van Berkel, J.J.; Dallinga, J.W.; Moller, G.M.; Godschalk, R.W.; Moonen, E.J.; Wouters, E.F.; van Schooten, F.J. A profile of volatile organic compounds in breath discriminates COPD patients from controls. Respir. Med. 2010, 104, 557-563. [CrossRef] [PubMed] 
32. Hakim, M.; Billan, S.; Tisch, U.; Peng, G.; Dvrokind, I.; Marom, O.; Abdah-Bortnyak, R.; Kuten, A.; Haick, H. Diagnosis of head-and-neck cancer from exhaled breath. Br. J. Cancer 2011, 104, 1649-1655. [CrossRef] [PubMed]

33. Itoh, T.; Miwa, T.; Tsuruta, A.; Akamatsu, T.; Izu, N.; Shin, W.; Park, J.; Hida, T.; Eda, T.; Setoguchi, Y. Development of an Exhaled Breath Monitoring System with Semiconductive Gas Sensors, a Gas Condenser Unit, and Gas Chromatograph Columns. Sensors 2016, 16, 1891-1906. [CrossRef] [PubMed]

34. Chawla, N.V.; Bowyer, K.W.; Hall, L.O.; Kegelmeyer, W.P. SMOTE: Synthetic minority over-sampling technique. J. Artif. Intell. Res. 2002, 16, 321-357.

35. Akbani, R.; Kwek, S.; Japkowicz, N. Applying support vector machines to imbalanced datasets. In Machine Learning: ECML 2004, Proceedings of the 15th European Conference on Machine Learning, Pisa, Italy, 20-24 September 2004; Springer: Berlin/Heidelberg, Germany, 2004; pp. 39-50.

36. Chawla, N.V. Data mining for imbalanced datasets: An overview. In Data Mining and Knowledge Discovery Handbook; Springer: Berlin/Heidelberg, Germany, 2005; pp. 853-867.

37. Bernhard, E.B.; Isabelle, M.G.; Vapnik, V.N. A training algorithm for optimal margin classifiers. In Proceedings of the Fifth Annual Workshop on Computational Learning Theory, Pittsburgh, PA, USA, 27-29 July 1992; pp. 144-152.

38. Furey, T.S.; Cristianini, N.; Duffy, N.; Bednarski, D.W.; Schummer, M.; Haussler, D. Support vector machine classification and validation of cancer tissue samples using microarray expression data. Bioinformatics 2000, 16, 906-914. [CrossRef] [PubMed]

39. Brown, M.P.; Grundy, W.N.; Lin, D.; Cristianini, N.; Sugnet, C.W.; Furey, T.S.; Ares, M.; Haussler, D. Knowledge-based analysis of microarray gene expression data by using support vector machines. Proc. Natl. Acad. Sci. USA 2000, 97, 262-267. [CrossRef] [PubMed]

40. Chai, H.; Domeniconi, C. An evaluation of gene selection methods for multi-class microarray data classification. In Proceedings of the Second European Workshop on Data Mining and Text Mining in Bioinformatics, Pisa, Italy, 20-24 September 2004; pp. 3-10.

41. McHardy, A.C.; Martin, H.G.; Tsirigos, A.; Hugenholtz, P.; Rigoutsos, I. Accurate phylogenetic classification of variable-length DNA fragments. Nat. Methods 2007, 4, 63-72. [CrossRef] [PubMed]

42. Yin, Z.; Sadok, A.; Sailem, H.; McCarthy, A.; Xia, X.; Li, F.; Garcia, M.A.; Evans, L.; Barr, A.R.; Perrimon, N. A screen for morphological complexity identifies regulators of switch-like transitions between discrete cell shapes. Nat. Cell Biol. 2013, 15, 860-871. [CrossRef] [PubMed]

43. Van't Veer, L.J.; Dai, H.; van de Vijver, M.J.; He, Y.D.; Hart, A.A.; Mao, M.; Peterse, H.L.; van der Kooy, K.; Marton, M.J.; Witteveen, A.T. Gene expression profiling predicts clinical outcome of breast cancer. Nature 2002, 415, 530-536. [CrossRef] [PubMed]

44. Ambroise, C.; McLachlan, G.J. Selection bias in gene extraction on the basis of microarray gene-expression data. Proc. Natl. Acad. Sci. USA 2002, 99, 6562-6566. [CrossRef] [PubMed]

45. Phillips, M.; Cataneo, R.N.; Condos, R.; Erickson, G.A.R.; Greenberg, J.; La Bombardi, V.; Munawar, M.I.; Tietje, O. Volatile biomarkers of pulmonary tuberculosis in the breath. Tuberculosis 2007, 87, 44-52. [CrossRef] [PubMed]

46. Fens, N.; Zwinderman, A.H.; van der Schee, M.P.; de Nijs, S.B.; Dijkers, E.; Roldaan, A.C.; Cheung, D.; Bel, E.H.; Sterk, P.J. Exhaled breath profiling enables discrimination of chronic obstructive pulmonary disease and asthma. Am. J. Respir. Crit. Care Med. 2009, 180, 1076-1082. [CrossRef] [PubMed]

47. Gilad-Bachrach, R.; Navot, A.; Tishby, N. Margin based feature selection-theory and algorithms. In Proceedings of the Twenty-First International Conference on Machine Learning, Banff, AB, Canada, 4-8 July 2004; pp. 144-152.

48. Navot, A.; Shpigelman, L.; Tishby, N.; Vaadia, E. Nearest neighbor based feature selection for regression and its application to neural activity. Adv. Neural Inf. Process. Syst. 2006, 18, 995-1002.

49. Klöppel, S.; Abdulkadir, A.; Jack, C.R.; Koutsouleris, N.; Mourão-Miranda, J.; Vemuri, P. Diagnostic neuroimaging across diseases. Neuroimage 2012, 61, 457-463. [CrossRef] [PubMed]

(C) 2017 by the authors; licensee MDPI, Basel, Switzerland. This article is an open access article distributed under the terms and conditions of the Creative Commons Attribution (CC BY) license (http:/ / creativecommons.org/licenses/by/4.0/). 